Check for updates

Cite this: RSC Adv., 2018, 8, 16858

Received 29th January 2018

Accepted 1st May 2018

DOI: $10.1039 / c 8 r a 00875 b$

rsc.li/rsc-advances

\section{Fully-automated magnetic stirring-assisted lab-in- syringe dispersive liquid-liquid microextraction for the determination of arsenic species in rice samples}

\author{
Xiaojun Wang, (D)* Guoliang Xu, Peng Chen, Yueshu Sun, Xiaoting Yao, Yan Lv, \\ Weiwei Guo and Guozhen Wang
}

Fully-automated magnetic stirring-assisted lab-in-syringe dispersive liquid-liquid microextraction (MASLIS-DLLME), combined with graphite furnace atomic absorption spectrometry (GFAAS) was developed for the fast and efficient separation and preconcentration of trace levels of inorganic arsenic species in rice samples. This totally automated analytical procedure combines the advantages of lab-in-syringe flow system and dispersive liquid-liquid microextraction (DLLME) aiming at separation of trace arsenite and arsenate species from natural matrix for the first time. With a single syringe pump that is coupled with a multiposition valve, the whole lab-in-syringe microextraction process including cleaning, mixing, microextraction, phase separation, and target analyte collection was implemented in a fully-automated way. Significant factors of the MAS-LIS-DLLME method were sample acidity, concentration of the chelating agent, amounts of ionic liquids (ILs), aspiration speed and matrix interference. Using the present method, the limits of detection (LODs) for As(v) was $0.005 \mu \mathrm{g} \mathrm{L}^{-1}$. The relative standard deviation (RSDs) for seven replicate measurements of $2.0 \mu \mathrm{g} \mathrm{L}^{-1}$ of $\mathrm{As}(\mathrm{v})$ was $3.7 \%$. The linear dynamic range (LDR) was $0.04-5.0 \mu \mathrm{g} \mathrm{L}^{-1}$ and the determination coefficients was 0.9990 . Under the optimum conditions, the developed totally automated analytical procedure was successfully applied for the trace arsenite and arsenate species studies in natural rice samples and standard reference materials with satisfactory results.

\section{Introduction}

Arsenic has been identified as a public health problem because it has serious toxic effects even at low exposure levels and is widespread in the environment. ${ }^{\mathbf{1}}$ Arsenic mainly occurs in two oxidation states, As(III) and As(v), each of which manifests different physicochemical properties and biochemical activity. In fact, it has been shown that As(III) is approximately 25-60 times more toxic than $\mathrm{As}(\mathrm{v})$ and, in comparison with organic arsenic forms, As(III) is several hundred times more toxic than organic arsenicals. Therefore, speciation of arsenic as a ubiquitous and potentially toxic element in complex matrix has become an interesting topic in food analysis.

In general, several element-specific and sensitive instrumental techniques ${ }^{2-11}$ have been successfully utilized for direct analysis of total amount of As at trace levels. To obtain information about the toxicities, biochemical, bioavailability and environmental behavior of arsenite and arsenate species, it is necessary to develop sensitive and selective methodologies for the qualitative and quantitative analysis of these individual inorganic arsenic species. However,

College of Civil Engineering and Architecture, Zhejiang University of Water Resources and Electric Power, 583 Xuelin Street, Hangzhou 310018, Zhejiang Province, People's Republic of China. E-mail: wangxiaoj@zjweu.edu.cn; Fax: +86 571 86926577; Tel: +86 57186926577 direct measurement of trace arsenite and arsenate by the abovementioned sensitive detection technique is limited due to matrix interference and insufficient sensitivity. To obtain information on species, separation and microextraction of arsenite and arsenate species are required prior to the spectrometric determination by an accessible, simple, inexpensive and sensitive nonchromatographic detection technique. In trace and ultratrace analysis, the separation and preconcentration steps are often required. For the speciation of trace arsenite and arsenate species from natural samples, the separation and microextraction methodologies reported in the literature are usually based on ion exchange, ${ }^{12}$ hydride generation, ${ }^{13}$ solid phase extraction (SPE) $)^{14,15}$ and liquid-liquid extraction (LLE) ${ }^{16}$ etc. Although drawbacks such as long extraction time, significant chemical additives, production of secondary wastes and multistage operation limit the use of these separation techniques. ${ }^{\mathbf{1 7}}$

In order to overcome the shortcomings of these methodologies, a novel mode of liquid phase microextraction (LPME) termed dispersive liquid-liquid microextraction (DLLME) was suggested by Rezaee and co-workers. ${ }^{17}$ In DLLME procedure, the extractant is dispersed into the sample solution as very fine droplets to form an emulsified solution. Such a strategy enables the mass transfer between the analytes and fine droplets of water-immiscible extractant and significantly enhanced the microextraction recoveries. The extension of the contact surface 
between the organic extraction solvent and sample solution could effectively reduce sample pretreatment time. ${ }^{18}$ The advantages of the DLLME technology are short extraction time, low cost, simplicity of operation and high microextraction recoveries. Various studies have been presented by the usage of DLLME method on the separation and microextraction for the elemental speciation analysis at trace levels. ${ }^{\mathbf{1 9 , 2 0}}$

In general, the main shortcomings of the conventional DLLME technology are the necessity of using extractant like chloroform, carbon tetrachloride, octanol and carbondisulfide, isolation of acceptor phase from water phase, loss of extractant containing the target analytes at the phase isolation process and low microextraction recoveries of the target analytes. However, the phase isolation step is considered to be the most time-consuming process in traditional DLLME technology. Some authors have reported that they have spent 15-20 min centrifuging each sample. ${ }^{\mathbf{2 1 , 2 2}}$ To overcome limitations mentioned above, very recently, a novel combined DLLME technology which is termed as lab-in-syringe dispersive liquid-liquid microextraction (LISDLLME $)^{23}$ was proposed and successfully applied for efficient analysis of dye rhodamine B from soft drinks. The so-called lab-insyringe systems combine the strategies of sequential injection systems $^{24}$ with flow-batch technologies, ${ }^{25}$ and the entire process of sample separation and microextraction and measurement can take place inside the integrated system..$^{26}$ In lab-in-syringe systems, chemical reactions between metal ions and complexing agents, and different operation steps like chelation, preconcentration or separation could perform inside the syringe barrel. ${ }^{27,28}$ Thus, the lab-in-syringe systems has been successfully used for various interesting designs in fully-automated DLLME for the determination of trace caffeine, ${ }^{26}$ heavy metals, ${ }^{27,28}$ and priority phenolic pollutants $^{29}$ from complex matrix.

In this paper, the applicability of fully-automated magnetic stirring-assisted lab-in-syringe dispersive liquid-liquid microextraction (MAS-LIS-DLLME) using 1-hexyl-3methylimidazoliumhexafluorophosphate $\quad\left(\left[\mathrm{C}_{6} \mathrm{MIM}\right]\left[\mathrm{PF}_{6}\right]\right)$ as extractant, to fast extract trace arsenite and arsenate species in natural rice samples, prior to their analysis by GFAAS was developed. However, to the best of our knowledge, this is the first reported combination of MAS-LIS-DLLME with atomic spectrometric assays for the inorganic arsenic speciation. The significant factors influencing the microextraction recoveries of MAS-LIS-DLLME, such as sample acidity, concentration of the chelating agent, amounts of ionic liquids (ILs), aspiration flow rate and matrix interference, were systematically tested, and the analytical performance of the proposed methodology was evaluated. Furthermore, the developed fully-automated DLLME procedure has been used for the preconcentration and speciation of trace arsenite and arsenate species from rice matrix with satisfactory results.

\section{Experimental}

Apparatus

The fully-automated DLLME system (Fig. 1) comprised a rotary 8-port multi-position valve (VICI, Schenkon, Switzerland) coupled to an automatic burette with a $10 \mathrm{~mL}$ syringe (Hamilton, Bonaduz, Switzerland) and a three-way solenoid valve

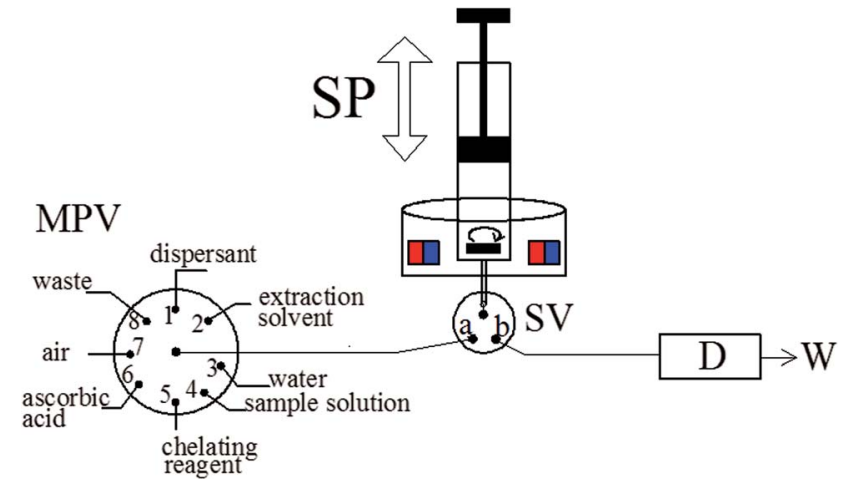

Fig. 1 The schematic of the MAS-LIS-DLLME system. D, detection system; SP, syringe pump; SV, three-way solenoid valve; W, waste; MPV, multiposition valve.

(Jiashan Ristron electronic technology Co., Ltd., Zhejiang, China) in the head section. Multiwave 3000 XF100 (Anton Paar, Graz, Austria) microwave digestion system was used for rice digestion. A research Delta 320 pH-meter (Mettler-Toledo, Zurich, Switzerland) were employed for measurement of $\mathrm{pH}$ values. The magnetic stirring system was composed by a lab made device and a small magnetic stirrer bar placed inside the syringe, as detailed in previous study. ${ }^{30}$ A Perkin-Elmer Model AAnalyst 800 atomic absorption spectrometer (Perkin-Elmer, USA) with Zeeman effect background correction was utilized as the detection system. An arsenic hollow cathode lamp operated at $6 \mathrm{~mA}$ was utilized as a radiation source. The spectral bandwidth was set at $0.7 \mathrm{~nm}$ and the wavelength was set at 193.7 $\mathrm{nm}$ resonance line. The detailed temperature program used for graphite atomizer is listed in Table 1. All tubing of the fully-automated DLLME systems was made from polytetrafluoroethylene (PTFE) tubing with $0.79 \mathrm{~mm}$ inner diameter.

\section{Standard solution and reagents}

All the chemicals used in this study were at least of analytical grade, and all solutions were prepared with ultrapure water obtained from a Milli-Q Element water system (Millipore Corporation, USA). Ammonium molybdate heptahydrate was obtained from the Sinopharm Chemical Reagent Corporation by (Shanghai,

Table 1 Graphite furnace temperature program

Operation parameters

Drying1

Drying2

Pyrolysis1

Pyrolysis2

Atomization

Cleaning
$110{ }^{\circ} \mathrm{C}$ (ramp $1 \mathrm{~s}$, hold $30 \mathrm{~s}$,

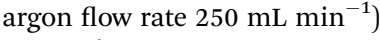
$130{ }^{\circ} \mathrm{C}$ (ramp $15 \mathrm{~s}$, hold $30 \mathrm{~s}$,

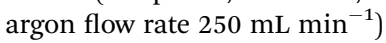
$600{ }^{\circ} \mathrm{C}$ (ramp $10 \mathrm{~s}$, hold $10 \mathrm{~s}$, $800{ }^{\circ} \mathrm{C}$ (ramp $5 \mathrm{~s}$, hold $10 \mathrm{~s}$, argon flow rate $250 \mathrm{~mL} \mathrm{~min}^{-1}$ ) $2200{ }^{\circ} \mathrm{C}$ (ramp $0 \mathrm{~s}$, hold $3 \mathrm{~s}$,

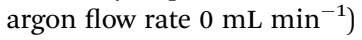
$2400{ }^{\circ} \mathrm{C}$ (ramp $1 \mathrm{~s}$, hold $3 \mathrm{~s}$,

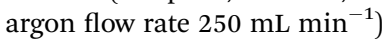
argon flow rate $250 \mathrm{~mL} \mathrm{~min}^{-1}$ ) 
China). Ionic liquid ([ $\left.\left.\mathrm{C}_{6} \mathrm{MIM}\right]\left[\mathrm{PF}_{6}\right]\right)$ was purchased from Shanghai Cheng Jie Chemical Co., Ltd., Shanghai, China. The solution of chelating agent, ammonium molybdate, was prepared daily by dissolving appropriate amount of ammonium molybdate heptahydrate in ultrapure water. The stock standards $\left(1000 \mathrm{mg} \mathrm{L}^{-1}\right)$ of inorganic arsenic species were prepared by dissolving appropriate amounts of $\mathrm{Na}_{3} \mathrm{AsO}_{3}$ and $\mathrm{As}_{2} \mathrm{O}_{5}$, respectively, (Sigma-Aldrich, St. Louis, MO, USA) in ultrapure water and storing the solutions in a refrigerator at $4{ }^{\circ} \mathrm{C}$. All vessels used for trace analysis were kept in $10 \%(\mathrm{v} / \mathrm{v})$ nitric acid for at least $24 \mathrm{~h}$ and washed three times with ultrapure water prior to use.

\section{Extraction procedures}

After adjusting the sample $\mathrm{pH}$ to 1.5 using diluted nitric acid/ ammonia, As(III) and As(v) were separated and enriched using the developed fully-automated DLLME methodology (MAS-LISDLLME) systems as follows. Initially, the cleaning of the syringe, magnetic stirring bar and connecting tube is done by the aspiration of $10 \mathrm{~mL}$ ultrapure water (MPV in position 3 and SV in position a) followed by discharge to waste (MPV in position 8) for three times. Afterwards, $5 \mathrm{~mL}$ of aliquots of the sample or standard solution (MPV in position 4), $0.1 \mathrm{~mL}$ of $40 \mathrm{mmol} \mathrm{L}^{-1}$ ammonium molybdate solution (MPV in position 5), $0.1 \mathrm{~mL}$ of $10 \mathrm{mmol} \mathrm{L}^{-1}$ ascorbic acid solution (MPV in position 6) and $1 \mathrm{~mL}$ of air (at MPV in position 7) were sequentially aspirated into the syringe. The aqueous solution and the mixture of chelating agent and analyte inside the syringe were stirred by $20 \mathrm{~s}$ for the complexing reaction development. Then, $500 \mu \mathrm{L}$ of methanol as the dispersant (MPV in position 1), $45 \mu \mathrm{L}$ of $\left[\mathrm{C}_{6} \mathrm{MIM}\right]\left[\mathrm{PF}_{6}\right]$ as the extraction solvent (MPV in position 2) and $1 \mathrm{~mL}$ of air (at MPV in position 7) were subsequently aspirated into the syringe. Next, the mixture of sample, dispersive solvents and extractant solvents was stirred by $30 \mathrm{~s}$ to accelerate the dispersion of $\left[\mathrm{C}_{6} \mathrm{MIM}\right]\left[\mathrm{PF}_{6}\right]$ and to enhance the separation and preconcentration of target analytes. Subsequently, the syringe pump and stirrer are stopped for $60 \mathrm{~s}$ enabling phase separation process, and then the extractant phase was sedimented at the bottom of the syringe. After that, the SV moves to position $\mathrm{b}$ and the extractant phase is dispensed into the flow cell for the subsequent graphite furnace atomic absorption spectrometric analysis of arsenic.

\section{Samples preparation}

All the commercially available rice samples of different varieties were acquired from local markets in Hangzhou, China and these rice samples were classified as follows: white rice, brown rice, parboiled rice, glutinous rice and rice flour. The rice samples were washed three times with ultrapure water, and then were dried at $60{ }^{\circ} \mathrm{C}$ in air oven. After that, the rice grains were milled by crushing and grinding to 100 mesh in a food processor. The resulting fine powder was stored at $4{ }^{\circ} \mathrm{C}$ in a dark environment prior to use.

Total arsenic was also measured as As(v) using the developed fully-automated DLLME method. Briefly, portions $(0.2000 \mathrm{~g})$ of resulting fine powder of the rice samples were accurately weighed into the PTFE vessel, then $4 \mathrm{~mL} \mathrm{HNO}_{3}(65 \%)$ and $2 \mathrm{~mL}$
$\mathrm{H}_{2} \mathrm{O}_{2}(30 \%)$ were added. The rice samples were digested with Multiwave 3000 XF100 (Anton Paar, Graz, Austria) microwave digestion system after the application of the microwave digestion procedure (the first stage: $600 \mathrm{~W}$ for $10 \mathrm{~min}(10 \mathrm{~min}$ of ramp); the second stage: $800 \mathrm{~W}$ for $10 \mathrm{~min}$ (10 min of ramp); the last cooling stage: $0 \mathrm{~W}$ for $15 \mathrm{~min}$ ) and then the resulting solutions were diluted to proper concentrations with ultrapure water.

The inorganic arsenic was also extracted from the rice samples using the developed ultrasound-assisted extraction method and measured as As(v) after oxidation reaction. The ultrasound-assisted extraction of inorganic arsenic from natural samples was proposed in some previous works. ${ }^{31,32}$ Briefly, $0.5 \mathrm{~g}$ of finely powdered rice sample was placed into a $50 \mathrm{~mL}$ polyethylene centrifuge tube. A total of $30 \mathrm{~mL} \mathrm{HNO}_{3}\left(0.5 \mathrm{~mol} \mathrm{~L}^{-1}\right)$ was added and the polyethylene centrifuge tube was subjected to sonication for $30 \mathrm{~min}$ at $40{ }^{\circ} \mathrm{C}$ to extract inorganic arsenic. After the ultrasonic extraction process, the acid extract was separated by centrifugation at $5000 \mathrm{rpm}$ for $5 \mathrm{~min}$. The supernatant was filtered through a $0.45 \mu \mathrm{m}$ pore size nylon membrane filter and then an aliquot of the supernatant solution was submitted to the developed fully-automated DLLME method for determination of As(v).

Selective oxidation of As(III) to As(v) was performed before the fully-automated DLLME process. The $\mathrm{KMnO}_{4}$ solution was added to the obtaining supernatant above in order to oxidize $\operatorname{As}(\mathrm{III})$ to $\mathrm{As}(\mathrm{v})$. The mixture was left to stand for $10 \mathrm{~min}$ with sonication assistant, and then the resulting solution was subjected to the developed fully-automated DLLME method for the measurement of total inorganic arsenic. In addition, the As(III) concentration was calculated by subtracting the As(v) concentration from the total inorganic As concentration.

\section{Results and discussion}

To obtain good sensitivity and precision, the effects of chemical and hydrodynamic parameters, including sample acidity, concentration of the chelating agent, amounts of ionic liquids (ILs) and aspiration flow rate, were thoroughly investigated in the present study. Standard solutions at $2.0 \mu \mathrm{g} \mathrm{L}^{-1} \mathrm{As}(\mathrm{III})$ and As(v) concentration level were applied for the optimization experiments and all the experiments were performed in triplicate.

\section{Effect of sample acidity}

The effect of the sample acidity on the metal-chelate formation and subsequent extraction into extractant phase was examined between the $\mathrm{pH}$ values $0.5-4.5$ (Fig. 2). As could be seen, the microextraction recovery of $\mathrm{As}(\mathrm{v})$ was increased rapidly with increasing sample solution acidity from 0.5 to 1.5 , and kept nearly constant in the $\mathrm{pH}$ range of $1.5-2.5$, then was decreased with further increasing $\mathrm{pH}$ from 2.5 to 4.5. Hence, highly selective separation and preconcentration of As(v) from As(III) can be achieved. For all subsequent experiments, the $\mathrm{pH}$ value of 1.5 was chosen to adjust samples and standards before fullyautomated DLLME process. 


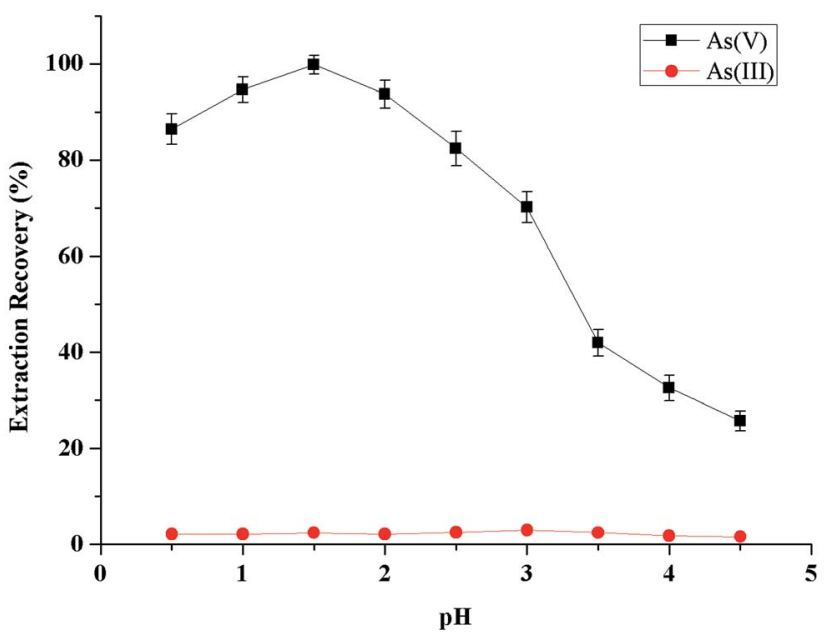

Fig. 2 Effect of sample acidity on the extraction recovery of inorganic arsenic obtained from the proposed MAS-LIS-DLLME method. Extraction conditions: sample volume, $5 \mathrm{~mL}$; concentration of inorganic arsenic, $2.0 \mathrm{ng} \mathrm{mL} \mathrm{m}^{-1}$; amount of ascorbic acid, $100 \mu \mathrm{L}$ of

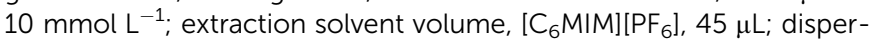
sive solvent volume, methanol, $500 \mu \mathrm{L}$; amount of ammonium molybdate, $100 \mu \mathrm{L}$ of $40 \mathrm{mmol} \mathrm{L}^{-1}$; sample aspiration speed, 2200 step $\mathrm{s}^{-1}$.

\section{Effect of ammonium molybdate concentration}

The influence of the concentration of ammonium molybdate as chelating reagent on the sensitivity was studied in the range 20$50 \mathrm{mmol} \mathrm{L}^{-1}$. As can be seen in Fig. 3, the microextraction recovery of $\mathrm{As}(\mathrm{v})$ increased by increasing the concentration of ammonium molybdate up to $40 \mathrm{mmol} \mathrm{L}^{-1}$, and then remained

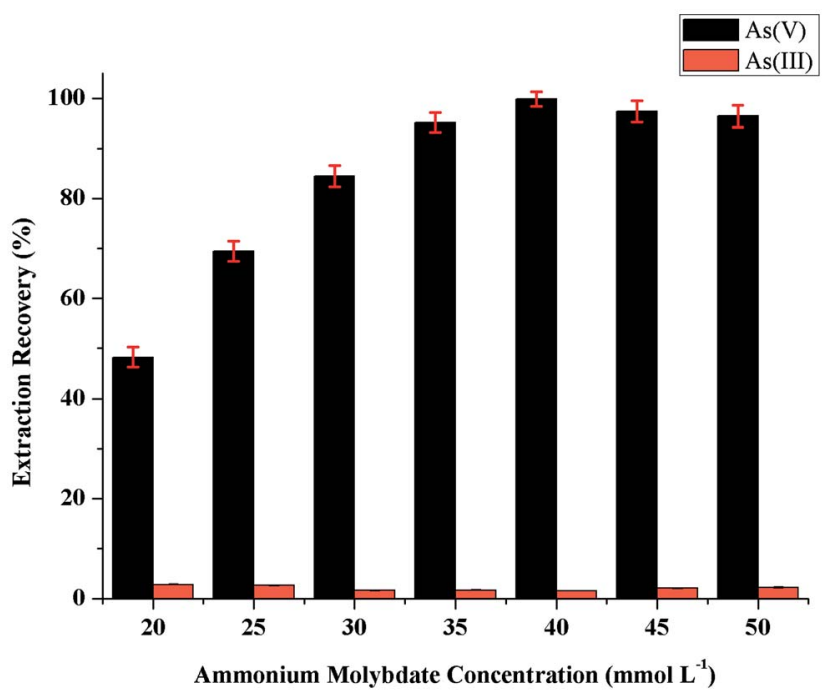

Fig. 3 Effect of ammonium molybdate concentration on the extraction recovery of inorganic arsenic obtained from proposed MAS-LISDLLME method. Extraction conditions: sample volume, $5 \mathrm{~mL}$; concentration of inorganic arsenic, $2.0 \mathrm{ng} \mathrm{mL}^{-1}$; amount of ascorbic

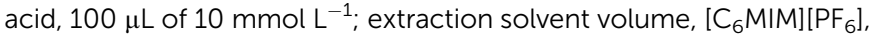
$45 \mu \mathrm{L}$; dispersive solvent volume, methanol, $500 \mu \mathrm{L}$; volume of ammonium molybdate, $100 \mu \mathrm{L}$; sample aspiration speed, 2200 step $\mathrm{s}^{-1}$. nearly constant. On the other hand, no amount of As(v) could be selectively extracted from As(III) in the absence of ammonium molybdate. Thus, a concentration of ammonium molybdate of $40 \mathrm{mmol} \mathrm{L} \mathrm{L}^{-1}$ was selected to obtain the highest extraction efficiency in the further study.

\section{Effect of the amount of extraction solvent}

Due to its non-volatile physicochemical properties, $\left[\mathrm{C}_{6} \mathrm{MIM}\right]$ $\left[\mathrm{PF}_{6}\right]$ is a suitable extraction solvent to form biphasic systems. The influence of ionic liquids amount on the microextraction recovery was also studied. For this purpose, $0.5 \mathrm{~mL}$ methanol with different amounts of $\left[\mathrm{C}_{6} \mathrm{MIM}\right]\left[\mathrm{PF}_{6}\right]$ (within the range of 20$60 \mu \mathrm{L}$ ) was used for highly selective separation and microextraction of As(v) from As(III). Fig. 4 shows that microextraction recovery of the developed fully-automated lab-in-syringe systems was affected significantly by $\left[\mathrm{C}_{6} \mathrm{MIM}\right]\left[\mathrm{PF}_{6}\right]$ amount; microextraction recovery increased with the amount of ionic liquids with the most $\mathrm{As}(\mathrm{v})$ recovered from $45 \mu \mathrm{L}$ of extraction solvent. An amount of $45 \mu \mathrm{L}\left[\mathrm{C}_{6} \mathrm{MIM}\right]\left[\mathrm{PF}_{6}\right]$ was marked as the optimum for the developed fully-automated DLLME procedure, while adding more $\left[\mathrm{C}_{6} \mathrm{MIM}\right]\left[\mathrm{PF}_{6}\right]$ have no significant changes in microextraction recovery.

\section{Effect of the speed of sample aspiration}

The speed of sample aspiration plays a unique role in the separation and preconcentration of As(v) from As(III) in natural samples. In this study, influence of the speed of sample aspiration on microextraction efficiency was investigated by in the range between 1100 and 2400 step s$^{-1}$ while the other experimental variables were kept constant. The obtained results showed that the microextraction recovery increased as the

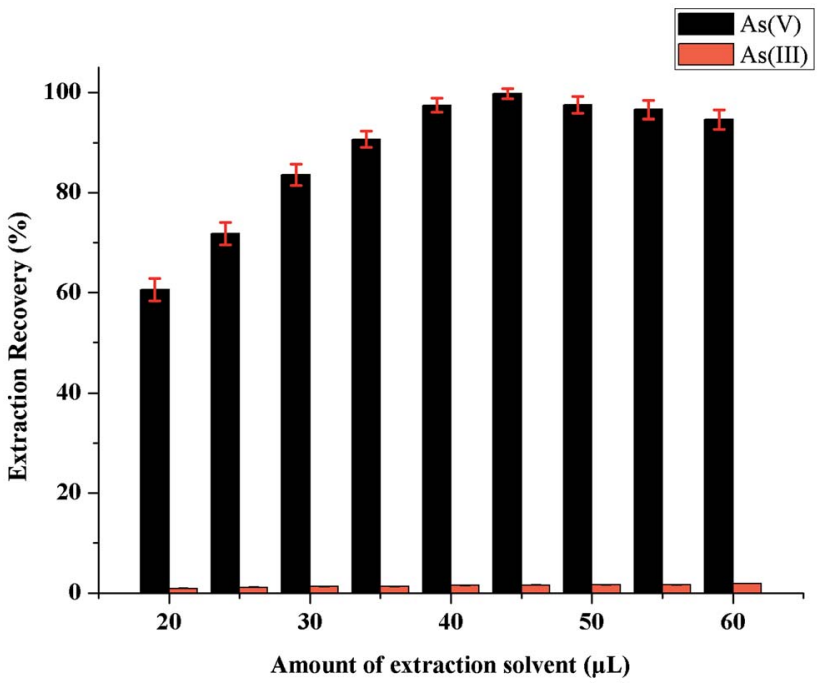

Fig. 4 Effect of the extraction solvent $\left(\left[\mathrm{C}_{6} \mathrm{mim}\right]\left[\mathrm{FeCl}_{4}\right]\right)$ volume on the extraction recovery of inorganic arsenic obtained from proposed MAS-LIS-DLLME method. Extraction conditions: sample volume, $5 \mathrm{~mL}$; concentration of inorganic arsenic, $2.0 \mathrm{ng} \mathrm{mL}^{-1}$; amount of ascorbic acid, $100 \mu \mathrm{L}$ of $10 \mathrm{mmol} \mathrm{L}^{-1}$; dispersive solvent volume, methanol, 500 $\mu \mathrm{L}$; amount of ammonium molybdate, $100 \mu \mathrm{L}$ of $40 \mathrm{mmol} \mathrm{L}^{-1}$; sample aspiration speed, 2200 step s$^{-1}$. 
Table 2 Effect of potential interfering ions on the recovery of $2.0 \mu \mathrm{g}$ $\mathrm{L}^{-1} \mathrm{As}(\mathrm{v})$

\begin{tabular}{llr}
\hline Interfering ions & Concentration $\left(\mathrm{mg} \mathrm{L}^{-1}\right)$ & Recovery $(\%)$ \\
\hline $\mathrm{Na}^{+}$ & 4000 & 96.7 \\
$\mathrm{~K}^{+}$ & 4000 & 95.2 \\
$\mathrm{Ca}^{2+}$ & 1500 & 101.8 \\
$\mathrm{Mg}^{2+}$ & 1500 & 96.3 \\
$\mathrm{Ba}^{2+}$ & 1500 & 98.6 \\
$\mathrm{Co}^{2+}$ & 5 & 101.3 \\
$\mathrm{Fe}^{2+}$ & 5 & 102.9 \\
$\mathrm{Mn}^{2+}$ & 5 & 99.4 \\
$\mathrm{Ni}^{2+}$ & 5 & 96.9 \\
$\mathrm{Zn}^{2+}$ & 5 & 106.7 \\
$\mathrm{Cu}^{2+}$ & 5 & 98.5 \\
$\mathrm{Cd}^{2+}$ & 5 & 97.1 \\
$\mathrm{~Pb}^{2+}$ & 2 & 104.8 \\
$\mathrm{Fe}^{3+}$ & 0.5 & 105.6 \\
$\mathrm{Cl}^{-}$ & 4000 & 94.3 \\
$\mathrm{SO}_{4}{ }^{2-}$ & 4000 & 102.8 \\
$\mathrm{NO}_{3}{ }^{2-}$ & 4000 & 106.9 \\
& &
\end{tabular}

speed of sample aspiration increased from 1100 to 2200 step $\mathrm{s}^{-1}$. The speed of sample aspiration of 2200 step $\mathrm{s}^{-1}$ was marked as the optimum for the fully-automated lab-in-syringe systems, while faster speed of sample aspiration has no significant changes in microextraction efficiency.

\section{Interferences}

To test the selectivity and sensitivity of the proposed fullyautomated DLLME procedure for the separation and preconcentration of $\mathrm{As}(\mathrm{V})$ from $\mathrm{As}(\mathrm{III})$ the influence of some potentially interfering anions $\left(\mathrm{SO}_{4}{ }^{2-}, \mathrm{Cl}^{-}\right.$and $\left.\mathrm{NO}_{3}{ }^{-}\right)$and cations $\left(\mathrm{K}^{+}, \mathrm{Na}^{+}, \mathrm{Ca}^{2+}, \mathrm{Mg}^{2+}\right.$ and $\left.\mathrm{Ba}^{2+}\right)$, which are concomitant and regularly found in complex matrix, was examined. In these experiments, $2.0 \mathrm{ng} \mathrm{mL} \mathrm{m}^{-1} \mathrm{As}(\mathrm{v})$ solution containing the added interferences was processed according to the recommended process under the optimum experimental condition. The tolerance limit was defined as the maximum concentration of interfering ions, in the presence of which the extraction recovery of $\mathrm{As}(\mathrm{v})$ could be maintained within the range of 90$110 \%$. As shown in Table 2, alkaline and alkaline earth metal ions such as $\mathrm{K}^{+}, \mathrm{Na}^{+}, \mathrm{Mg}^{2+}$ and $\mathrm{Ba}^{2+}$, and anions including $\mathrm{SO}_{4}{ }^{2-}, \mathrm{Cl}^{-}$and $\mathrm{NO}_{3}{ }^{-}$did not influence the As(v) extraction efficiency at the experimental concentrations (extraction recoveries 94.3-106.9\%). The tolerance limits of $\mathrm{Ni}^{2+}, \mathrm{Co}^{2+}, \mathrm{Pb}^{2+}$ and $\mathrm{Fe}^{3+}$ were not as high as other coexisting ions, mainly because those common metal ions can react with chelating agent at working $\mathrm{pH}$. Therefore, the excessive ammonium molybdate as chelating reagent was necessary in this test. Since the concentrations of coexisting ions were generally at trace levels in natural matrix, this developed fully-automated DLLME method may be suitable for the separation and microextraction of $\mathrm{As}(\mathrm{v})$ from $\mathrm{As}(\mathrm{III})$ in rice matrix.

\section{Analytical performance}

Under the optimum experimental conditions, the analytical characteristics of the established fully-automated DLLME method were tested and limits of detection (LOD), relative standard deviation (RSD), and linear dynamic ranges (LDR) are given in Table 3. The precision of this established fullyautomated DLLME method was determined by analyzing standard solution at $2.0 \mathrm{ng} \mathrm{mL} \mathrm{m}^{-1} \mathrm{As}(\mathrm{v})$ for seven replicate extraction and measurements and the relative standard deviation (RSD) was $3.7 \%{ }^{34}$ The limits of detection (LOD), which is defined as $C_{\mathrm{LOD}}=3 S_{\mathrm{d}} / m$ (where $\mathrm{C}_{\mathrm{LOD}}, S_{\mathrm{d}}$ and $m$ are LOD, standard deviation of the blank, and slope of the calibration graph, respectively) according to the IUPAC definition, was $0.005 \mathrm{ng} \mathrm{mL}^{-1}$ for $\operatorname{As}(\mathrm{v})$. The calibration graph was linear within the range of 0.04$5.0 \mathrm{ng} \mathrm{mL} \mathrm{m}^{-1}$ of $\mathrm{As}(\mathrm{v})$, with a correlation of coefficient $(r)$ of 0.9990 .

A comparison of the developed fully-automated DLLME method with other previously published methods is summarized in Table 3. It clearly shows that the developed fullyautomated DLLME method has good sensitivity, selectivity and precision with a low sample consumption in comparison to in situ solvent formation microextraction (ISFME), cloud point

Table 3 Comparison of MAS-LIS-DLLME with other microextraction methods reported in the literature for arsenic determination

\begin{tabular}{|c|c|c|c|c|c|c|}
\hline Method & Detection & $\mathrm{LOD}^{a}$ & RSD (\%) & $\mathrm{LDR}^{b}$ & Sample & Ref. \\
\hline MAS-LIS-DLLME & GFAAS & 0.005 & 3.7 & $0.04-5.0$ & Rice & This work \\
\hline $\mathrm{CPE}^{c}$ & ETAAS & 0.009 & 2.5 & $0.05-10.0$ & Rice & 32 \\
\hline DLLME & ETV-ICP-MS $^{d}$ & 0.0025 & 9.7 & $0.01-10$ & Environmental water & 33 \\
\hline ISFME $^{e}$ & ETAAS & 0.006 & 4.78 & $0.02-0.250$ & Saline samples & 34 \\
\hline IL-DLLME $^{f}$ & ETAAS & 0.005 & 4.7 & $0.05-6$ & Wine & 35 \\
\hline USAE-SFODME ${ }^{g}$ & ETAAS & 0.004 & 6.1 & $0.05-2$ & Environmental water & 36 \\
\hline SPE-DLLME-SFO $^{h}$ & GFAAS & 0.0025 & 6.8 & $0.01-0.1$ & Water & 37 \\
\hline HF-LPME ${ }^{i}$ & ETAAS & 0.12 & 8 & $1-50$ & Fresh waters and human hair & 38 \\
\hline $\mathrm{SPE}^{j}$ & ETAAS & 0.02 & 3.5 & $0.03-0.6$ & Water & 39 \\
\hline AC-Modified-KR ${ }^{k}$ & ETAAS & 0.004 & 4.3 & $0.01-1.5$ & Medicinal herbs and tea infusions & 40 \\
\hline
\end{tabular}

${ }^{a}$ Limit of detection $\left(\mu \mathrm{g} \mathrm{L}{ }^{-1}\right) .{ }^{b}$ Linear dynamic range $\left(\mu \mathrm{g} \mathrm{L}{ }^{-1}\right) .{ }^{c}$ Cloud point extraction. ${ }^{d}$ Electrothermal vaporization inductively coupled plasma mass spectrometry. ${ }^{e}$ In situ solvent formation microextraction. ${ }^{f}$ Ionic liquid-based dispersive liquid-liquid microextraction. ${ }^{g}$ Ultrasound assisted emulsification of solidified floating organic drop microextraction. ${ }^{h}$ Solid phase extraction-dispersive liquid-liquid microextraction based on the solidification of floating organic drop. ${ }^{i}$ Hollow fiber-liquid phase microextraction. ${ }^{j}$ Solid phase extraction. ${ }^{k}$ Activated carbon-modified knotted reactor. 
Table 4 Recovery of added inorganic arsenic species to different rice samples by MAS-LIS-DLLME method

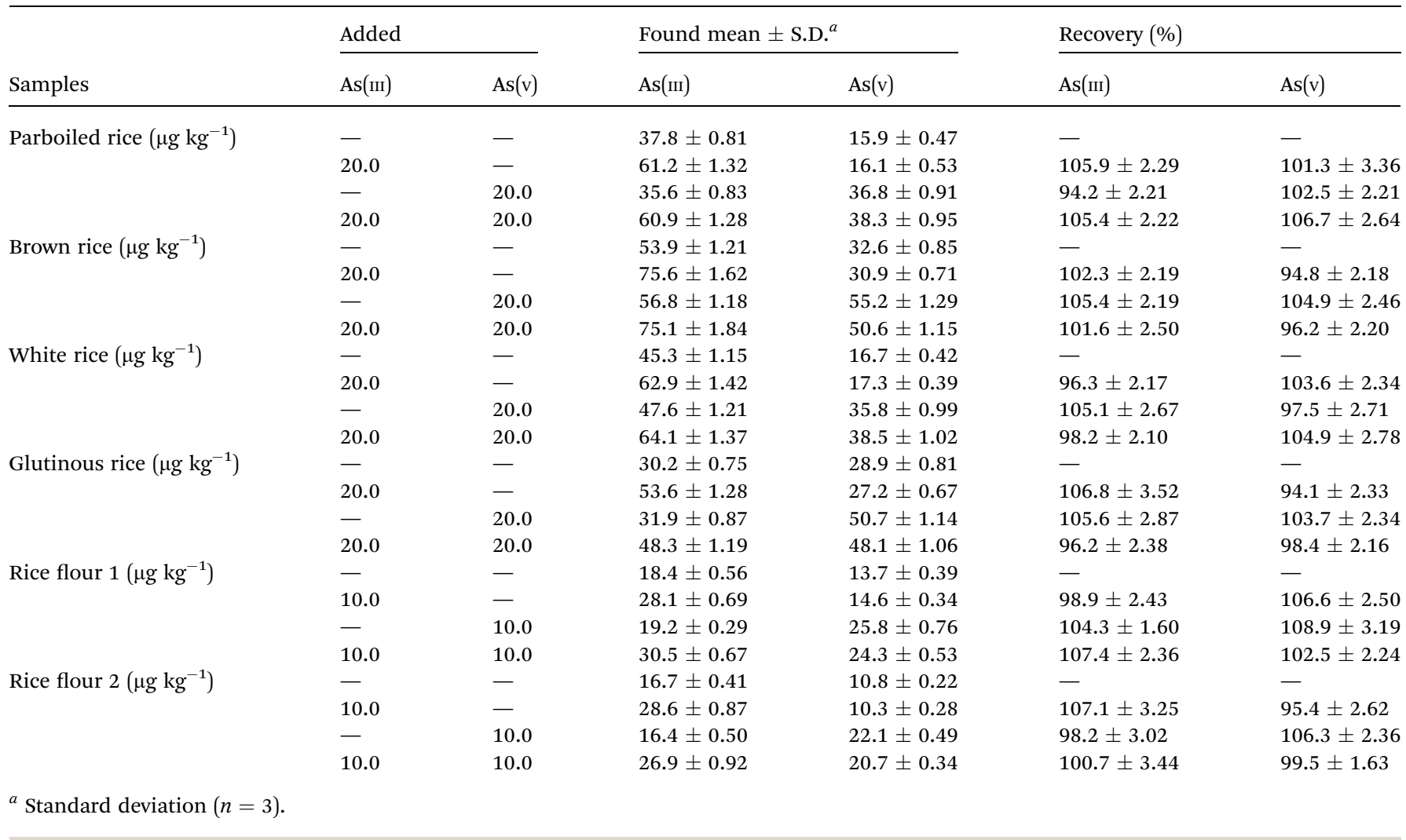

extraction (CPE), hollow fiber-liquid phase microextraction (HFLPME) and solid phase extraction (SPE). In contrast to many previous studies, the LDR of the represented fully-automated DLLME method is acceptable compared with other methodologies. The LOD of the proposed process was comparable to those of other published microextraction methodologies whilst the obtained RSD was better than dispersive liquid-liquid microextraction (DLLME), hollow fiber-liquid phase microextraction (HF-LPME), ultrasound assisted emulsification of solidified floating organic drop microextraction (USAESFODME) and solid phase extraction-dispersive liquid-liquid microextraction based on the solidification of floating organic drop (SPE-DLLME-SFO) considered in the comparison.

\section{Analysis of real samples}

The proposed fully-automated DLLME method was used for separation and preconcentration of $\operatorname{As}(\mathrm{v})$ from $\mathrm{As}(\mathrm{III})$ in some

Table 5 The total arsenic contents of certified reference materials obtained by MAS-LIS-DLLME method $\left(\mu \mathrm{g} \mathrm{g}^{-1} \text {, mean } \pm \text { S.D. }\right)^{a}$

\begin{tabular}{lccr}
\hline Samples & Found & Certified value & $t$-Test \\
\hline GBW10010 (Rice) & $0.105 \pm 0.006$ & $0.102 \pm 0.008$ & 0.704 \\
GBW10043 (Liaoning rice) & $0.117 \pm 0.015$ & $0.114 \pm 0.018$ & 0.866 \\
GBW10044 (Sichuan rice) & $0.11 \pm 0.02$ & $0.12 \pm 0.03$ & 0.701 \\
${ }^{a}$ Standard deviation $(n=3)$. & & &
\end{tabular}

natural rice matrix. Moreover, the accuracy of the results was verified by spiking known amount of As(III) and As(v) in different rice samples, including parboiled rice, white rice, brown rice, glutinous rice and rice flour. The obtained results were presented in Table 4 . As could been seen, the extraction efficiencies for the spiked samples were in acceptance range (94.2-108.9\%), which confirms the reliability of the developed fully-automated DLLME method and its independence from the complex matrix effect.

\section{Accuracy of the method}

To validate the accuracy of the developed fully-automated DLLME methodology, several standard reference materials (GBW10010 rice, GBW10043 Liaoning rice and GBW10044 Sichuan rice) were detected, and the content of total As are summarized in Table 5 . As could be seen, the analyzed values $\left(0.105 \pm 0.006,0.117 \pm 0.015\right.$ and $0.11 \pm 0.02 \mu \mathrm{g} \mathrm{g} \mathrm{g}^{-1}$ for three replicate measurements) found by using the developed fullyautomated DLLME method for GBW10010 rice, GBW10043 Liaoning rice and GBW10044 Sichuan rice were statistically in good agreement with the certified values of $0.102 \pm 0.008,0.114$ \pm 0.018 and $0.12 \pm 0.03 \mu \mathrm{g} \mathrm{g}{ }^{-1}$, respectively. As the certified values of standard reference materials were within the $95 \%$ confidence interval around the mean of the analyzed values, there is no significant difference between the values. It can be concluded that the developed fully-automated DLLME methodology is sensitive, selective, reliable and free from systematic errors. 


\section{Conclusion}

In the present work, fully-automated magnetic stirring-assisted lab-in-syringe dispersive liquid-liquid microextraction (MASLIS-DLLME) coupled with graphite furnace atomic absorption spectrometry (GFAAS) was successfully employed for highly selective separation and preconcentration of trace arsenite and arsenate species in natural rice samples. Ammonium molybdate and 1-hexyl-3-methylimidazoliumhexafluorophosphate $\left(\left[\mathrm{C}_{6} \mathrm{MIM}\right]\left[\mathrm{PF}_{6}\right]\right)$ were chosen as a chelating reagent and extractant in MAS-LIS-DLLME, respectively. The developed fullyautomated DLLME methodology (MAS-LIS-DLLME) has some distinct advantages such as sensitive, selective, high extraction capacity, simple operation, low cost and rapid mass transfer. The combination of MAS-LIS-DLLME with GFAAS was shown to be alternative for the quantification of trace arsenite and arsenate species in relatively complicated matrices with good accuracy and reproducibility.

\section{Compliance with ethics requirements}

This article does not contain any studies with human or animal subjects.

\section{Conflicts of interest}

Xiaojun Wang, Guoliang Xu, Peng Chen, Yueshu Sun, Xiaoting Yao, Yan Lv, Weiwei Guo, Guozhen Wang declare that they have no conflict of interest.

\section{Acknowledgements}

This work was supported by the Zhejiang Provincial Soft Science Research Project under Grant number 2018C35027; and Zhejiang Provincial Public Technology Application Research Project under Grant number 2017C33060; and Research Project of Zhejiang Association of Social Sciences under Grant number 2018N20; and Hangzhou Philosophy and Social Science Program under Grant number Z17JC078.

\section{References}

1 T. S. Choong, T. G. Chuah, Y. Robiah, F. G. Koay and I. Azni, Desalination, 2007, 217, 139-166.

2 G. M. dos Santos, D. Pozebon, C. Cerveira and D. P. de Moraes, Microchem. J., 2017, 133, 265-271.

3 H. I. Ulusoy, M. Akçay and R. Gürkan, Talanta, 2011, 85, 1585-1591.

4 C. Zeng, Y. Yan, J. Tang, Y. Wu and S. Zhong, Spectrosc. Lett., 2017, 50, 220-226.

5 A. F. M. Y. Haider, M. H. Ullah, Z. H. Khan, F. Kabir and K. M. Abedin, Opt. Laser Technol., 2014, 56, 299-303.

6 S. Döker, L. Uzun and A. Denizli, Talanta, 2013, 103, 123-129.

7 J. Michon, V. Deluchat, R. Al Shukry, C. Dagot and J. C. Bollinger, Talanta, 2007, 71, 479-485.

8 F. J. Pereira, M. D. Vázquez, L. Debán and A. J. Aller, Talanta, 2016, 152, 211-218.
9 E. Bolea-Fernandez, L. Balcaen, M. Resano and F. Vanhaecke, Anal. Bioanal. Chem., 2015, 407, 919-929.

10 P. Heitland, M. Blohm, C. Breuer, F. Brinkert, E. G. Achilles, I. Pukite and H. D. Köster, J. Trace Elem. Med. Biol., 2017, 41, 36-40.

11 N. Phattamajintatamrong, M. Puanngam and A. Imyim, Curr. Anal. Chem., 2017, 13, 137-143.

12 S. Jeong, H. Lee, Y. T. Kim and H. O. Yoon, Microchem. J., 2017, 134, 295-300.

13 T. D. Çiftçi and E. Henden, Bull. Environ. Contam. Toxicol., 2016, 97, 272-278.

14 K. Hagiwara, T. Inui, Y. Koike, M. Aizawa and T. Nakamura, Talanta, 2015, 134, 739-744.

15 V. G. Mihucz, L. Bencs, K. Koncz, E. Tatár, T. Weiszburg and G. Záray, Spectrochim. Acta, Part B, 2017, 128, 30-35.

16 R. Güell, C. Fontàs, V. Salvadó and E. Anticó, Sep. Purif. Technol., 2010, 72, 319-325.

17 M. Rezaee, Y. Assadi, M. R. M. Hosseini, E. Aghaee, F. Ahmadi and S. Berijani, J. Chromatogr. A, 2006, 1116, 1-9.

18 Z. G. Shi and H. K. Lee, Anal. Chem., 2010, 82, 1540-1545.

19 L. Elçi, A. Elçi, T. A. Berg and J. F. Tyson, Int. J. Environ. Anal. Chem., 2013, 93, 1065-1073.

20 S. Rabieh, M. Bagheri and B. Planer-Friedrich, Microchim. Acta, 2013, 180, 415-421.

21 L. M. Ravelo-Pérez, J. Hernández-Borges, M. Asensio-Ramos and M. Á. Rodríguez-Delgado, J. Chromatogr. A, 2009, 1216, 7336-7345.

22 Q. Zhou, N. Zhao and G. Xie, J. Hazard. Mater., 2011, 189, 4853.

23 F. Maya, B. Horstkotte, J. M. Estela and V. Cerdà, Anal. Bioanal. Chem., 2012, 404, 909-917.

24 J. Ruzicka and G. D. Marshall, Anal. Chim. Acta, 1990, 237, 329-343.

25 P. H. G. D. Diniz, L. F. de Almeida, D. P. Harding and M. C. U. de Araújo, TrAC, Trends Anal. Chem., 2012, 35, 3949.

26 R. M. Frizzarin, F. Maya, J. M. Estela and V. Cerdà, Food Chem., 2016, 212, 759-767.

27 B. Horstkotte, K. Fikarová, D. J. Cocovi-Solberg, H. Sklenářová, P. Solich and M. Miró, Talanta, 2017, 173, 79-87.

28 R. Sánchez, B. Horstkotte, K. Fikarova, H. Sklenářová, S. Maestre, M. Miró and J. L. Todolí, Anal. Chem., 2017, 89, 3787-3794.

29 A. González, J. Avivar and V. Cerdà, Anal. Bioanal. Chem., 2015, 407, 2013-2022.

30 B. Horstkotte, R. Suárez, P. Solich and V. Cerdà, Anal. Chim. Acta, 2013, 788, 52-60.

31 J. F. Paula, R. E. Froes-Silva and V. S. Ciminelli, Microchem. J., 2012, 104, 12-16.

32 B. E. dos Santos Costa, N. M. M. Coelho and L. M. Coelho, Food Chem., 2015, 178, 89-95.

33 Y. Liu, M. He, B. Chen and B. Hu, Talanta, 2015, 142, 213220.

34 B. Majidi and F. Shemirani, Biol. Trace Elem. Res., 2011, 143, 579-590. 
35 L. B. Escudero, E. M. Martinis, R. A. Olsina and R. G. Wuilloud, Food Chem., 2013, 138, 484-490.

36 M. Asadollahzadeh, N. Niksirat, H. Tavakoli, A. Hemmati, P. Rahdari, M. Mohammadi and R. Fazaeli, Anal. Methods, 2014, 6, 2973-2981.

37 M. Shamsipur, N. Fattahi, Y. Assadi, M. Sadeghi and K. Sharafi, Talanta, 2014, 130, 26-32.
38 H. Jiang, B. Hu, B. Chen and L. Xia, Anal. Chim. Acta, 2009, 634, 15-21.

39 I. López-García, R. E. Rivas and M. Hernández-Córdoba, Talanta, 2011, 86, 52-57.

40 A. C. Grijalba, E. M. Martinis, G. E. Lascalea and R. G. Wuilloud, Spectrochim. Acta, Part B, 2015, 103, 49-56. 